\title{
HIGH SERUM CRP IN ACUTE ISCHEMIC STROKE PATIENT AS A PREDICTOR FOR WORSE OUTCOME DURING HOSPITALIZATION
}

\section{Gondowardaya, Y, Nuartha AABN, Purwata TE, Budiarsa IGN, Kusuma Putra IB}

Department of Neurology, Medical School , Udayana University / Sanglah Hospital Denpasar, Bali, Indonesia

ABSTRACT

\section{Background and aims}

Stroke is the most devastating disease worldwide. Mortality rate of hemorrhagic stroke is higher than ischemic one, but it confined to poor short and long term outcome. Several studies have searched for any parameters that can predict for poor outcome, one of which is inflammation process. Neuroinflammation process lead to inconvenient effect in progression of cerebral ischemia, although, it also give benefit in healing and repairing phase of nerve cells. This study aimed at testing that high serum CRP could act as an inflammation marker that confined to predict outcome in acute ischemic stroke during hospitalization.

\section{Methods}

This was an analytic observational study with cohort prospective design. Outcome was classified into two groups, good and worse outcome based on NIHSS score at the time of admission and on the 7th day of care. Inflammation rate was examined by measuring CRP value.

\section{Results}

A total of 110 eligible patients of ischemic stroke met to this study during July until October 2013. Data analyzed by SPSS 16.0 for windows showed several characters of subject, including age, sex, onset of stroke, type of ischemic stroke, prior systolic and diastolic blood pressure, infection, and death rate during hospitalization.

CRP, leucocyte, neutrophil, and ESR (erythrocyte sedimentation rate) value, were determined as subject character. Comparative between high serum CRP and poor outcome during hospitalization tested with Chi Square and revealed a statistically significance value $(p<0,001)$ with Relative Risk (RR) $=14,143$ $(95 \% \mathrm{Cl}, 5,248-38,115)$.

\section{Conclusion}

This study significantly proved that high serum CRP was a predictor for worse outcome during hospitalization in acute ischemic stroke patients.

Table 1. Subject characteristics

\begin{tabular}{|c|c|c|c|c|c|c|}
\hline \multirow[t]{2}{*}{ Characteristics } & \multicolumn{2}{|c|}{$\begin{array}{l}\text { High CRP } \\
(>10 \mathrm{mg} / \mathrm{L}) \\
(\mathrm{n}=52)\end{array}$} & \multicolumn{2}{|c|}{$\begin{array}{c}\text { Normal CRP } \\
\text { ( } \leq 10 \mathrm{mg} / \mathrm{L}) \\
(\mathrm{n}=51)\end{array}$} & \multirow[t]{2}{*}{$\mathbf{p}$} & \multirow{2}{*}{$\begin{array}{c}\text { Total } \\
(n=103) \\
n(\%)\end{array}$} \\
\hline & $n$ & $\%$ & $n$ & $\%$ & & \\
\hline Age (years) & \multicolumn{2}{|c|}{$60,19 \pm 12,25$} & \multicolumn{2}{|c|}{$59,35 \pm 12,97$} & 0,200 & \\
\hline \multicolumn{7}{|l|}{ Sex } \\
\hline - Male & 25 & $(42,4)$ & 34 & $(57,6)$ & $<0,001$ & 59 (100) \\
\hline - Female & 27 & $(61,4)$ & 17 & $(38,6)$ & & $44(100)$ \\
\hline \multicolumn{7}{|l|}{ Onset of stroke } \\
\hline$-<6$ hours & 14 & $(51,9)$ & 13 & $(48,1)$ & \multirow{3}{*}{$<0,001$} & $27(100)$ \\
\hline - 6-24 hours & 15 & $(42,9)$ & 20 & $(57,1)$ & & $35(100)$ \\
\hline - 24-72 hours & 23 & $(56,1)$ & 18 & $(43,9)$ & & $41(100)$ \\
\hline \multicolumn{7}{|l|}{ Type of ischemic stroke } \\
\hline - Thrombosis & 13 & $(23,6)$ & 42 & $(76,4)$ & $<0,001$ & $55(100)$ \\
\hline - Embolic & 39 & $(81,2)$ & 9 & $(18,8)$ & & $48(100)$ \\
\hline \multicolumn{7}{|l|}{ NIHSS 1} \\
\hline - Mild stroke & 2 & $(8,3)$ & 22 & $(91,7)$ & \multirow{3}{*}{0,021} & $24(100)$ \\
\hline - Moderate stroke & 36 & $(56,2)$ & 28 & $(43,8)$ & & $64(100)$ \\
\hline - Moderate-severe stroke & 14 & $(93,3)$ & 1 & $(6,7)$ & & $15(100)$ \\
\hline
\end{tabular}

Table 2. Subject characteristics based on outcome

\begin{tabular}{|c|c|c|c|c|c|c|}
\hline \multirow[t]{2}{*}{ Characteristics } & \multicolumn{2}{|c|}{$\begin{array}{l}\text { Worse outcome } \\
\qquad(n=43)\end{array}$} & \multicolumn{2}{|c|}{$\begin{array}{l}\text { Good outcome } \\
\qquad(n=60)\end{array}$} & \multirow[t]{2}{*}{$\mathbf{p}$} & \multirow{2}{*}{$\begin{array}{c}\text { Total } \\
(n=103) \\
n(\%)\end{array}$} \\
\hline & $\mathrm{n}$ & $\%$ & $\mathrm{n}$ & $\%$ & & \\
\hline Age (years) & \multicolumn{2}{|c|}{$62,79 \pm 11,77$} & \multicolumn{2}{|c|}{$57,62 \pm 12,76$} & 0,200 & \\
\hline $\begin{array}{l}\text { Sex } \\
\text { - Male } \\
\text { - Female } \\
\end{array}$ & $\begin{array}{l}22 \\
21\end{array}$ & $\begin{array}{l}(37,3) \\
(47,7)\end{array}$ & $\begin{array}{l}37 \\
23\end{array}$ & $\begin{array}{l}(62,7) \\
(52,3)\end{array}$ & $<0,001$ & $\begin{array}{l}59(100) \\
44(100)\end{array}$ \\
\hline $\begin{array}{c}\text { Onset of stroke } \\
-<6 \text { hours } \\
-6-24 \text { hours } \\
-\quad 24-72 \text { hours } \\
\end{array}$ & $\begin{array}{l}13 \\
11 \\
19\end{array}$ & $\begin{array}{l}(48,1) \\
(31,4) \\
(46,3)\end{array}$ & $\begin{array}{l}14 \\
24 \\
22\end{array}$ & $\begin{array}{l}(51,9) \\
(68,6) \\
(53,7)\end{array}$ & $<0,001$ & $\begin{array}{l}27(100) \\
35(100) \\
41(100)\end{array}$ \\
\hline $\begin{array}{l}\text { Type of ischemic stroke } \\
\text { - Thrombosis } \\
\text { - Embolic } \\
\end{array}$ & $\begin{array}{l}12 \\
31\end{array}$ & $\begin{array}{l}(21,8) \\
(64,6)\end{array}$ & $\begin{array}{l}43 \\
17\end{array}$ & $\begin{array}{l}(78,2) \\
(35,4)\end{array}$ & $<0,001$ & $\begin{array}{l}55(100) \\
48(100)\end{array}$ \\
\hline $\begin{array}{l}\text { Infection } \\
\text { - Yes } \\
\text { - No }\end{array}$ & $\begin{array}{c}9 \\
34\end{array}$ & $\begin{array}{l}(100) \\
(36,2)\end{array}$ & $\begin{array}{c}0 \\
60\end{array}$ & $\begin{array}{c}(0) \\
(63,8)\end{array}$ & $<0,001$ & $\begin{array}{c}9(100) \\
94(100)\end{array}$ \\
\hline $\begin{array}{r}\text { Death } \\
- \text { Yes } \\
- \text { No }\end{array}$ & $\begin{array}{l}10 \\
33\end{array}$ & $\begin{array}{l}(100) \\
(33,5)\end{array}$ & $\begin{array}{c}0 \\
60\end{array}$ & $\begin{array}{c}(0) \\
(64,5)\end{array}$ & $<0,001$ & $\begin{array}{l}10(100) \\
95(100)\end{array}$ \\
\hline $\begin{array}{l}\text { Blood Pressure } \\
\text { - Systolic (mmHg) } \\
\text { - Diastolic (mmHg) }\end{array}$ & \multicolumn{2}{|c|}{$\begin{array}{c}154,07 \pm 27,65 \\
93,49 \pm 13,78\end{array}$} & \multicolumn{2}{|c|}{$\begin{array}{c}156,33 \pm 28,82 \\
90,17 \pm 15,68\end{array}$} & $\begin{array}{l}0,44 \\
0,06\end{array}$ & \\
\hline $\begin{array}{l}\text { NIHSS } 1 \\
\text { - Mild stroke } \\
\text { - Moderate stroke } \\
\text { - Moderate-severe stroke }\end{array}$ & $\begin{array}{c}2 \\
32 \\
9\end{array}$ & $\begin{array}{l}(8,3) \\
(50) \\
(60)\end{array}$ & $\begin{array}{c}22 \\
32 \\
6\end{array}$ & $\begin{array}{c}(91,7) \\
(50) \\
(40)\end{array}$ & 0,021 & $\begin{array}{l}24(100) \\
64(100) \\
15(100)\end{array}$ \\
\hline $\begin{array}{l}\text { NIHSS } 2 \\
\text { - Normal } \\
\text { - Mild stroke } \\
\text { - Moderate stroke } \\
\text { - Moderate-severe stroke } \\
\text { - Severe stroke }\end{array}$ & $\begin{array}{c}0 \\
1 \\
29 \\
3 \\
10\end{array}$ & $\begin{array}{c}(0) \\
(3,2) \\
(58) \\
(100) \\
(100)\end{array}$ & $\begin{array}{c}9 \\
30 \\
21 \\
0 \\
0\end{array}$ & $\begin{array}{c}(100) \\
(96,8) \\
(42) \\
(0) \\
(0)\end{array}$ & $<0,001$ & $\begin{array}{c}9(100) \\
31(100) \\
50(100) \\
3(100) \\
10(100)\end{array}$ \\
\hline Leukocytes $\left(x 10^{3} / \mu \mathrm{L}\right)$ & \multicolumn{2}{|c|}{$12,3(6,99-17,26)$} & \multicolumn{2}{|c|}{$8,77(4,65-24)$} & $<0,008$ & \\
\hline Neutrophils $\left(\times 10^{3} / \mu \mathrm{L}\right)$ & \multicolumn{2}{|c|}{$8,9(4,29-15,2)$} & \multicolumn{2}{|c|}{$6,25(3,21-21,61)$} & $<0,004$ & \\
\hline LED 1 (mm/hour) & \multicolumn{2}{|c|}{$2,9(0-10)$} & \multicolumn{2}{|c|}{$1,00(0-10)$} & $<0,001$ & \\
\hline LED 2 (mm/hour) & \multicolumn{2}{|c|}{$25(2-65)$} & \multicolumn{2}{|c|}{$13(2-60)$} & $<0,001$ & \\
\hline CRP (mg/L) & \multicolumn{2}{|c|}{$20,2(0,5-64,1)$} & \multicolumn{2}{|c|}{$4,8(0,27-41,1)$} & $<0,001$ & \\
\hline
\end{tabular}

Figure 1. Bivariate analysis of CRP levels and outcome during hospitalization ( $p<0,001$; RR 14,143; 95\% Cl Min. 5248, Max. 38.115).

High CRP

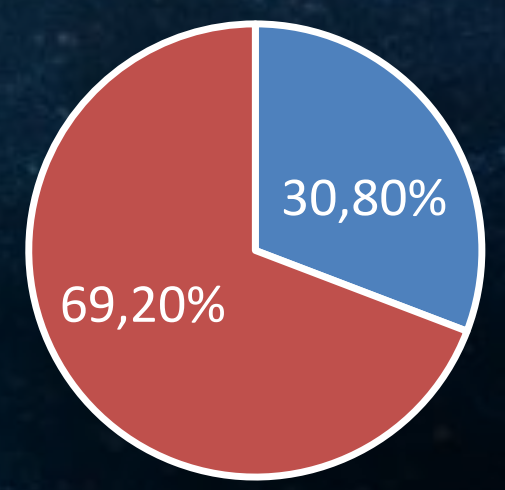

Normal CRP

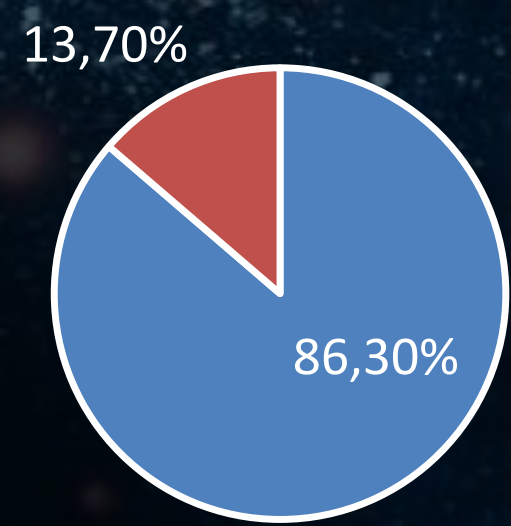

